\title{
An Analysis of Verbal Numerical Aptitude: An Untold Story of Students in West Sumatera
}

\author{
Yeni Afrida ${ }^{1}$, Absharini Kardena $^{2}$, Gema Hista Medika $^{3}$, Fadhilla Yusri ${ }^{4}$ \\ \{yeniafrida664@gmail.com ${ }^{1}$, absharinikardena@yahoo.co.id ${ }^{2}$, \\ gemahistamedika@gmail.com ${ }^{3}$, fadhillayusri@gmail.com $\left.{ }^{4}\right\}$
}

Faculty of Tarbiyah dan Teacher Training, Institut Agama Islam Negeri (IAIN) Bukittinggi, Indonesia $\mathrm{i}^{1,2,3,4}$

\begin{abstract}
Gender is believed to be one of factors that influence verbal aptitude and numerical aptitude. However, nowadays there are findings which reveal and seem breaking this belief. This research was conducted to prove the concepts related to gender in relation to the verbal aptitude and also numerical aptitude. The data of the research were collected from 633 respondents who are male and female. The research was used non parametric test by using U-test which found Sig 2 tailed 0,846 on verbal aptitude and 0,081 on numerical aptitude. The results of this study is there is no significant difference among verbal aptitude and numerical aptitude on male and female. Furthermore, it is assumed that the concept related to the difference of verbal and numerical aptitude cannot be generalized and it could be appeared on certain culture only.
\end{abstract}

Keywords. verbal, numerical, aptitude, gender

\section{Introduction}

Many issues related to gender are always interesting to be discussed. One of issues that always discussed is related to gender and the differences aptitudes. The difference aptitude between male and female has been suspected for a long time. This difference is always related to cognitive ability. Byrnes and Takahira, for instance, stated that "gender differences exist because male students may carry out certain cognitive aspects (e.g., knowledge access, strategy assembly) more effectively than female students".[1]. One gender is more superior to the other gender because the former is assumed to be better than the last, and vice versa. Furthermore, culture also contributes to be the other variable which influences the difference of aptitudes.

Among the discussions of aptitudes, one of interesting topics is related to verbal aptitude and numerical aptitudes. These two aptitudes are two among academic aptitudes that can be identified. Verbal aptitudes is related to an ability in comprehending ideas in forms of words while numerical aptitude is an ability in comprehending ideas in forms of number. Charter said that verbal aptitude is the capacity for general lexical skills, the understanding of words and the ability to use them effectively, meanwhile, numerical aptitude is general mathematical skills, working with numbers quickly and accurately [2]. When it is compared to research discussions, they can be illustrated as qualitative versus quantitative research. There are many previous researchers that have conducted the research in terms of gender in relation to verbal and numerical aptitudes. One of them is researches that found an influential of gender to verbal and 
numerical aptitudes [3][4][1][5][6][7]. Besides, there were also researches that found cultural factor as one of factors that influence verbal and numerical aptitudes. [8][9]. However, those researches were conducted in different times and different places. In fact, those researches found some findings, they are: 1.) male is better on numerical aptitude, 2) female is better on verbal aptitude, and 3) certain cultures are beliveved be better than other cultures in terms of verbal aptitude and numerical aptitude. However, the findings above have been questioned nowadays (at least for some aspects), such as about the difference of gender and verbal aptitude. Although at the prior researches it was found that female are better than male in verbal aptitude, at this time it does not really appear anymore [3], as what also occurred on gender, cultural background and numerical aptitude. It is also found that the influence of gender on numerical aptitude just appears on certain cultural only [10]. Much earlier, Clark \& Grandy [11], also began to maletion these indications in their research. They state "this study concludes that sex-related SAT differences are very small relative to the generally similar levels of performance by man and female". This research was conducted based on suspicion towards the generalization of gender differences in verbal and numerical aptitudes. The concept of the influence of gender on verbal and numerical aptitude may not be generalized to all situations and conditions. If in some countries there are differences in results, so what about in Indonesia? Is it the same? Or different? Furthermore, this study is aimed to prove 1) is there any difference between verbal and numerical aptitude in male and female? 2) is it true that male are superior to numerical aptitude than female? 3) is it true that female have verbal aptitude more superior than male? 4) or does differences in verbal and numerical aptitudes between male and female only exist and apply to certain situations and cultures.

\section{Method}

This research is a comparative quantitative study that is aimed to compare verbal and numerical aptitudes based on gender. The research data were taken from the results of the Scholastic Test (Scholastic Aptitude Test) of 633 students in several schools in West Sumatra; 308 were male, and 325 were female. The Scholastic Aptitude Test itself is a plural test used to find out a person's verbal and numerical aptitudes. This test consists of 90 items in which 50 questions are used to measure verbal aptitude and 40 other questions are aimed to measure numerical aptitude. Each question is done in 30 minutes. The data collected were then analyzed by using Non-Parametric Statistics in the form of the Mann Whitney test.

\section{Findings}

Table 1. Test Statistics ${ }^{\mathrm{a}}$

\begin{tabular}{ccc}
\hline \multicolumn{3}{c}{ Test Statistics $^{\mathbf{a}}$} \\
& Verbal Aptitude & Numerical Aptitude \\
\hline Mann-Whitney U & 49604.500 & 46038.500 \\
Wilcoxon W & 102579.500 & 93624.500 \\
Z & -.194 & -1.746 \\
Asymp. Sig. (2-tailed) & .846 & .081 \\
\hline
\end{tabular}

This table provides a general description that there are no significant difference between verbal and numerical aptitude in male and female (although the data show an average 
difference between the scores of verbal and numerical aptitudes between both male and female). There is no gender that is more superior to other gender related to verbal and numerical aptitude. It can be seen from Sig 2 tailed 0.846 on verbal aptitude and 0.081 on numerical aptitude. This conclusion was obtained after comparing the Sig 2 tailed value with $\alpha$ 0.05 .

\section{Discussion}

Human being is the most perfect creation from the God. One of the perfections is human has innate talent in which one of them is aptitude. Although Einstein said "I have no special aptitude, I am only passionately curious", pretending that he had no aptitude, in this case he has aptitude which is his curiosity. Warren in dictionary of psychology define aptitude as "a condition or set of characteristics regarded as symtomatic of an individual's ability to acquire with training some (usually specified knowledge, skill or set of responses), such as the ability to speak language, to produce mucic, etc". Based on those definitions, aptitude can be defined as "present characteristics that are symptomatic of future potentialities"[8]. Although these definitions have been defined a few decades ago, those definitions are still acceptable till now. The future potential can be "seen" from aptitude existing now. From the definitions above, it can be said that people with certain aptitudes are lucky people who "cheat." In other words, those people are the ones who spend a little effort but they can still achieve good results just like to the ones who do not have "the special aptitude", if it can't be called better. People with these aptitudes only need minimal effort to achieve maximum results. Once again, they are lucky people "who cheat".

In other definition, it is said that aptitude is the uniqueness that distinguishes one individual from another individual [12]. Furthermore, the diversity of aptitude in individuals is influenced by several things, including heredity and environmental factors. In terms of heredity, variations in genes and chromosomes inherited by individuals also cause some variations in their aptitude. In addition, the factors of parenting, socioeconomic conditions, interactions and environment become environmental factors that can affect aptitude. [13] In other words, whether aptitude is the factor that distinguishes one individual from another individual; whether aptitudes is a specific talents or not based on those definitions above, one thing for sure is the aptitude is a thing that should be developed as well. Related to the aptitude, many experts have tried to identify individual innate aptitude by using many kinds of inventory. It results many unique aptitudes, whether it is academic aptitude such as special, mechanic, abstract thinking, or even non-academic such as music and so on. Verbal and numerical aptitudes are among the aptitudes that have been identified. Verbal aptitude is related to the ability to understand and express concepts in the form of words, while numerical aptitude is the ability to understand and express concepts in the form of numbers.

In education world, aptitudes (especially academic aptitude) are believed as the best predictor to predict people successful as it also occurred on verbal and numerical aptitudes. Verbal and numerical aptitudes are believed to have an extraordinary contribution to academic success because of their position as the basic abilities which are needed to understand the subject [14]. Not surprisingly, so many researchers are intrigued to search and find more information related to verbal and numerical aptitudes. This research is one of them.

In relation to the discussion above, this study found four findings. The first finding is related to the difference among male and female in verbal and numerical aptitude. Data from this study indicate that there is no difference in verbal and numerical aptitude between male 
and female (with Sig 2 tailed 0.846 on verbal aptitude and 0.081 on numerical aptitude). These results also answer any doubts that have been previously stated in the introduction. The second finding is related to gender bias on numerical aptitude. Based on the data of this study, it can be said that "there is no gender bias related to verbal and numerical aptitude". The research found that male is not superior to female in numerical aptitude. Moreover, the third finding, in line with the previous finding, the study also found that female is not superior to male in verbal aptitude (although studies on gender and differences in aptitude and behavior that began in the 1880 s generally conclude the opposite), the studies concluded that "female's smaller brains were sadly deficient"[15]. Male are destined to be superior because their brain size is bigger. It seems that this conclusion does not apply to this study. Perhaps cognitive difference between male and female has really disappeared, as expressed by Feingold in 1988 [16], who agreeing point that has been previously expressed by Clark \& Grandy [11].

The findings above answer the following questions which relates to the truth of claims about the superiority of male in numerical aptitude over female, and the superiority of female in verbal aptitude compared to male It can be ascertained, based on data from the results of this study, that no one gender is superior to other genders, not on verbal aptitude, nor on numerical aptitude, against what has been discovered by previous researchers, such as Benbow and Stanley (1980) or Goldman and Hewitt (1976) on numerical aptitude [6][17]. Goldman and Hewitt through their research entitled "the scholastic aptitude test" explain why college men major in science are more often than college women, indirectly describing alignments with men in numerical aptitude, and so do Benbow and Stanley. These researchers still found the same conclusion. Benbow and Stanley strongly stated that "a substansial sex difference in mathematical reasoning ability (score on the mathematics test of the scholastic aptitude test) in favor of boys was found in a study of 9927 intellectually gifted junior high school student" [17][6]. Related to the claim of superiority of male, especially in numerical aptitude, it has actually been denied by Spelke (2005). In his review of sex differences in intrinsic aptitude for mathematics and science, Spelke said "research on cognitive development in human infants, preschool children, and students at all levels fails to support these claims. Instead, it provides evidence that mathematical and scientific reasoning develop from a set of biologically based cognitive capacities that males and females share. These capacities lead men and women to develop equal talent for mathematics and science." This research finding strengthens what has been stated previously by Spelke. [18]

If in numerical aptitude male are claimed to be superior then verbal aptitude is found the opposite claim that women are superior. Nevertheless, the result of this study does not find the truth of the claim. Perhaps Deborah's strong criticism is highly in accordance with the findings of this study. Deborah said in her study entitled "unanswer questions and unquestiones assumptions in the study of language and gender: female verbal superiority", that "I argue that this assumption relies on a selective and in some cases very accurate reading of the relevant linguistic evidence" [19]. This statement clearly states and also questions the claims of female excellence in verbal aptitude. Besides the finding which is different to the previous researches, the fourth results of this study also strengthen and prove the assumptions of Byrnes which says that gender differences in scholastic aptitude tests especially math sub-tests (verbal and numerical in this case) may be culture specific. [10] The United States and several other countries might have results that strengthen the superiority of male over female in verbal and numerical aptitude, but the same case is not found in Indonesia (other countries are also possible), West Sumatra at least in this region; not on verbal aptitude nor on numerical aptitude. In other words, the generalization of research results cannot yet be done. 


\section{Conclusion}

The data of this study prove that there is no significant difference between verbal and numerical aptitudes in male and female. There is no gender bias related to verbal and numerical aptitudes. Nevertheless, in-depth study, re-analysis, re-interpretation of gender and verbal and numerical aptitudes are still needed and need to be continued. It is intended to get the latest research results from a more diverse perspective of course. In addition, other notes obtained from this research in relation to different settings, different cultures, can contribute to find any different research result.

\section{References}

[1] J. P. Byrnes and S. Takahira, "Explaining Gender Differences on SAT-Math Items," Dev. Psychol., vol. 29, no. 5, pp. 805-810, 1993.

[2] P. Charter, IQ and Aptitude Tests. London: Kogan Page Limited, 2007.

[3] M. C. Hyde, Janet S.,Linn, "Gender Differences in Verbal Ability: A Meta-analysis.," pp. 53-69, 1988.

[4] C. David C, Beidleman \& Christine L, "Scholastic Aptitude Test Gender Gap," Am. Second. Educ., vol. 19, no. 2, pp. 2-5, 1991.

[5] W. C. Mau and R. Lynn, "Gender Differences on The Scholastic Aptitude Test, The American College Test and College Grades,” Educ. Psychol., vol. 21, no. 2, pp. 133-136, 2001.

[6] J. Benbow, C.P, Stanley, "Sex Differences in mathematical ability: fact or adtifact," Science (80-. )., vol. 210, no. 4475, pp. 1262-1264, 1980.

[7] J. Campbell, "Testing of Culturally Different Groups,” New Jersey, 1964.

[8] Charles M. Lucas, "Survey of The Literature Relating to The Effects of Cultural Backround on Aptitude Scores," ETS Res. Rep. Ser., vol. 1953, no. 2, pp. 1-64, 1953.

[9] M. Zeider, "Gender and Culture Interaction Effects on Scholastic Aptitude Test Performance: Some Israeli Findings,” J. Psychol., vol. 22, no. 1, pp. 11-119, 1987.

[10] J. P. Byrnes, L. Hong, and S. Xing, "Gender Differences on the Math Subtest of the Scholastic Aptitude Test May be Culture-Specific,” Educ. Stud. Math., vol. 34, no. 1, pp. 49-66, 1997.

[11] M. J. Clark and J. Grandy, "Sex Differences in the Academic Performance of Scholastic Aptitude Test Takers," ETS Res. Rep. Ser., vol. 1984, no. 2, p. i-27, 1984.

[12] A. A. Jung, R. E., Ryman, S. G., Vakhtin and R. A. Carraso, J., Wertz, C., \& Flores, "Subcortical correlates of individual differences in aptitude," Plus One, vol. 9, no. 2, pp. 1-9, 2014.

[13] L. D. Sauce, B., \& Matzel, "The causes of variation in learning and behavior: why individual difference matter," Front. Psychol., vol. 4, no. 396, pp. 1-10, 2013.

[14] A. A. Oyetunde, "Construction and validation of a general science aptitude test (GSAT) for Nigerian junior secondary school graduate," Iorin J. Educ., vol. 27, no. 1, pp. 22-23, 2007.

[15] J. S. Hyde, Janet S. Mertz, "Gender, Culture and Mathematics Performance," PNAS, vol. 106, no. 22, pp. 8801-8807, 2009.

[16] A. Feingold, "Cognitive Gender Differences are Disappearing," Am. Psychol., vol. 43, no. 2, pp. 95-103, 1988.

[17] B. N. Goldman, R. D., \& Hewitt, "The Scholastic Aptitude Test 'explains' why college men major in science more often than college women,” J. Couns. Psychol., vol. 23, no. 1, pp. 50-54, 1976.

[18] E. S. Spelke, "Sex Differences in Intrinsic Aptitude for Mathematics and Science?: A Critical Review," Am. Psychol., vol. 60, no. 9, pp. 950-958, 2005.

[19] D. Cameron, "Unanswer questions and unquestiones assumptions in the study of language and gender: female verbal superiority," Gend. Lang., vol. 1, no. 1, pp. 15-25, 2007. 